JKEP

Vol 5, No 2, November 2020

ISSN: 2354-6042 (Print)

ISSN : 2354-6050 (Online)

\title{
Penerapan Auricular Acupressure Untuk Mengurangi Konstipasi Pasien Kemoterapi
}

\author{
Edianto $^{1}$, Agung Waluyo², Sri Yona ${ }^{2}$, Yunisar Gultom ${ }^{3}$ \\ ${ }^{1}$ H. Adam Malik Central General Hospital Medan; \\ ${ }^{2}$ Faculty of Nursing, Universitas Indonesia, \\ ${ }^{3}$ Cipto Mangunkusumo Hospital, Jakarta Indonesia \\ Email : edianto.tok@gmail.com
}

\author{
Artikel history \\ Dikirim, Jul 29th 2020 \\ Ditinjau, Nov $6^{\text {th }}, 2020$ \\ Diterima, Nov $29^{\text {th }}, 2020$
}

\begin{abstract}
Most cancer patients receive chemotherapy which contributes to prolong life, with the most common side effects of constipation. Constipation causes general symptoms that are bad and affect the quality of life of patients. The purpose of evidance based nursing (EBN) is to identify the effectiveness of Auricular acupressure in overcoming symptoms of constipation in cancer patients receiving chemotherapy. This EBN uses quasi experiments involving 14 participants in the chemotherapy treatment room with pre and post intervention assessments. The results of the analysis of the independent t-test showed that there was a significant difference in the form of faeces on day 6 with $p<0.000$ (95\% CI). Conclusion: Auricular acupressure can be used as a constipation management nursing intervention in cancer patients undergoing chemotherapy.
\end{abstract}

Keywords:auricular acupressure, constipation, chemotherapy

\begin{abstract}
Abstrak
Sebagian besar pasien kanker mendapat kemoterapi yang berkontribusi untuk memperpanjang usia, dengan efek samping yang paling umum konstipasi. Konstipasi menyebabkan gejala umum yang buruk dan mempengaruhi kualitas hidup pasien. Tujuan evidence based nursing (EBN) untuk mengidentifikasi efektivitas Auricular acupressure dalam mengatasi gejala konstipasi pada pasien kanker yang mendapatkan kemoterapi. EBN ini menggunakan quasi eksperimen tanpa kontrol yang melibatkan 14 partisipan di ruang perawatan kemoterapi rumah sakit umum pusat nasional Cipto Mangunkusumo Jakarta dengan penilaian pre dan post intervensi. Penelitian ini dilakukan pada bulan April 2018 dengan hasil analisis uji independent $t$-test bahwa ada perbedaan signifikan bentuk feses pada hari ke 6 dengan p<0.000 (CI 95\%). Kesimpulan: Auricular acupressure dapat dijadikan intervensi keperawatan manajemen konstipasi pada pasien kanker yang menjalani kemoterapi.
\end{abstract}

Kata Kunci: auricular acupressure , konstipasi, kemoterapi 


\section{PENDAHULUAN}

Kanker merupakan penyebab utama morbiditas dan mortalitas pasien, secara signifikan berkontribusi terhadap meningkatnya beban pelayanan kesehatan di seluruh dunia (World Health Organization, 2015). Menurut World Health Organization (2015) hampir 14 juta kasus kanker baru terdiagnosis pada 2012, dan 8,2 juta kasus memburuk dalam waktu dua tahun (Badan Internasional untuk Penelitian Kanker (IARC), 2014). Selanjutnya, kejadian kanker diperkirakan akan meningkat sekitar 70\% selama dua dekade berikutnya (Papastavrou et al, 2016).

Sebagian besar pasien kanker payudara mendapat kemoterapi setelah mereka menjalani mastektomi. Meskipun kemoterapi berkontribusi untuk memperpanjang usia, kemoterapi disertai dengan efek samping yang parah seperti kehilangan nafsu makan, mual, dan muntah. Efek samping tersebut mengurangi total asupan makanan pasien, mengurangi mobilitas, dan menyebabkan konstipasi melalui peningkatan penggunaan obat antiemetik dan penghilang rasa sakit (J. H. Park, Jun, Kang, Joung, \& Kim, 2009). Sebuah penelitian terhadap pasien kanker payudara yang menjalani kemoterapi menemukan bahwa efek samping yang paling umum adalah konstipasi (52\%). Studi lain juga mengungkapkan bahwa konstipasi adalah salah satu efek samping paling umum dan menyakitkan dari pengobatan kanker (Hanai et al., 2016; Montemurro et al., 2016).

Konstipasi menyebabkan gejala fisik yang parah seperti obstruksi usus dan gejala psikologis seperti kecemasan dan stres. Konstipasi memiliki dampak negatif pada kualitas hidup; dengan demikian diperlukan langkah-langkah yang tepat untuk intervensi (Belsey, Greenfield, Candy, \& Geraint, 2010). Pasien kanker biasanya menggunakan banyak obat yang bertujuan untuk mengurangi efek samping kemoterapi tetapi lebih memilih tindakan intervensi nonfarmakologis (Hanai et al., 2016). Konstipasi lebih sering terjadi pada pasien kanker wanita, biasanya 5 sampai 8 hari setelah kemoterapi, karena penurunan peristaltik yang merupakan efek dari pengobatan (S. H. Kim, Lee, \& Lee, 2009).

Konstipasi pada pasien kanker payudara dapat diatasi dengan pemberian terapi auricular acupressure. Auricular acupressure adalah metode untuk mendiagnosis dan mengobati disfungsi fisik dan psikosomatis dengan merangsang titik tertentu di telinga (Gori \& Firenzuoli, 2007). 
Stimulasi telinga melibatkan refleks menjalani kemoterapi siklus ke 2 atau lebih neurologis, neurotransmiter, sitokin, sistem kekebalan tubuh, dan peradangan (Gori \& Firenzuoli, 2007; Zhao et al, 2012; Lin \& Hsieh, 2014). Terapi auricular-akupresur adalah aplikasi akupresur pada titik-titik tekanan telinga untuk membantu pergerakan lambung dan usus. Proses ini memperbaiki gejala konstipasi dan mendorong sirkulasi darah untuk membantu peristaltik dan memungkinkan buang air besar (Suen, Wong, Chung, \& Yip, 2007; Yan, Chui, \& Yang, 2005). Terapi ini adalah intervensi nonacupunctur untuk mengurang konstipasi yang menyebabkan rasa sakit dan efek samping, dan dengan demikian merupakan metode intervensi klinis yang efektif (Lee \& Frazier, 2011).

\section{METODE}

Penerapan EBN menggunakan metode quasi eksperimen. Penulis melakukan penilaian sebelum dan sesudah perlakua dengan jumlah partisipan sebanyak 14 orang. Pemilihan partisipan berdasarakan kriteria inkluasi pasien berusia 18 tahun ke atas, dapat berkomunikasi dengan baik, pasien dengan semua jenis kanker dan sedang yang mengalami konstipasi dan bersedia untuk terlibat dalam penerapan EBN. Sedangkan kriteria eksklusi adalah pasien dengan kelainan kongenital pada daun telingan dan pasien dengan luka pada daun telinga. EBN ini dilaksanakan di Ruang kemoterapi rawat jalan, Ruang Gedung A $\begin{array}{llllll}\text { lantai } & 4 & \text { dan } & 8 & \text { RSUPN } & \text { Cipto }\end{array}$ Mangunkusumo Jakarta pada bulan April 2019.

Penerapan EBN dengan melakukan penilaian dengan instrument Bristol Stool Form, kemudian menempelkan plester auricular dengan biji vaccaria diaplikasikan pada tujuh acupoint: usus, rektum, San Jiao, limpa, paru-paru, simpatik, dan subkorteks. Setiap area ditekan dengan keras sampai partisipan dapat merasakan sedikit tingkat rasa sakit. Peserta kemudian diinstruksikan untuk secara manual merangsang area yang diterapkan dengan biji 3 hingga 4 kali sehari, setelah 5 hari, biji vaccaria langsung dilepaskan. Kemudian dilaukan evaluasi terhadap tingkat konstipasi pada pasien dengan instrumen Bristol Stool Form setiap hari sampai hari ke 21. 


\section{Hasil}

Tabel 1 Distribusi Rata-rata Usia Partisipan yang Mendapatkan Terapi Auricular Acupressure di RSUPN Cipto Mangunkusumo, April 2109 ( $\mathrm{n}=14)$

\begin{tabular}{llll}
\hline Variabel & Mean & SD & Min-Mak \\
\hline Usia & 47,36 & 10,966 & $32-73$ \\
\hline
\end{tabular}

Berdasarkan tabel 1 di atas menunjukkan adalah 47,36 tahun. Dimana usia 47,36 tahun bahwa rata-rata usia partisipan pada tergolong pada usia dewasa madya. penerapan EBN Auricular Acupressure

Tabel 2 Distribusi Frekuensi Partisipan Berdasarkan Pendidikan, Pekerjaan dan Status Pernikahan Responden yang Mendapatkan Terapi Auricular Acupressure di RSUPN Cipto Mangunkusumo, April 2019 (n=14)

\begin{tabular}{lcc}
\hline \multicolumn{1}{c}{ Variabel } & $\begin{array}{c}\text { Frekuensi } \\
(\mathbf{n})\end{array}$ & $\begin{array}{c}\text { Persentase } \\
(\mathbf{\%})\end{array}$ \\
\hline Pendidikan & 2 & 14,3 \\
SD & 9 & 64,3 \\
SLTA & 3 & 21,4 \\
PT & $\mathbf{1 4}$ & $\mathbf{1 0 0}$ \\
\hline Total & & \\
\hline Pekerjaan & 4 & 28,6 \\
IRT & 2 & 14,3 \\
Pensiunan PNS & 8 & 57,1 \\
Wiraswasta & $\mathbf{1 4}$ & $\mathbf{1 0 0}$ \\
\hline Total & 13 & 92,9 \\
\hline Status Pernikahan & 1 & 7,1 \\
Menikah & $\mathbf{1 4}$ & $\mathbf{1 0 0}$ \\
Belum Menikah & & \\
\hline Total & 6 & 42,86 \\
\hline Jenis Kemoterapi & 2 & 14,29 \\
Cisplatin-5FU & 2 & 14,29 \\
CAF & 1 & 7,14 \\
Novalbion-Xeloda & 1 & 7,14 \\
Carboplatin-5FU & 1 & 7,14 \\
RDHAP & 1 & 7,14 \\
Cycloposfamid-Dexa & $\mathbf{1 4}$ & $\mathbf{1 0 0}$ \\
FOLFOX-6 & & \\
\hline Total & &
\end{tabular}

Hasil analisis univariat pada tabel 2 wiraswasta yaitu sebanyak 8 orang $(57,1 \%)$, menunjukkan bahwa mayoritas pendidkan dan hampir semua partisipan sudah menikah partisipan adalah SLTA yaitu 9 orang yaitu sebanyak 13 orang $(92,9 \%)$. Sementara (64,3\%), mayoritas pekerjaan adalah itu sebagian besar yaitu sebanyak 6 orang 
$(42,86 \%) \quad$ mendapatkan kemoterapi

cisplatin-5FU.

Tabel 3 Distribusi Rata-Rata Konstipasi Partisispan Sebelum dan Sesudah dilakukan Auricular Acupressure di RSUPN Cipto Mangunkusumo, April 2019 (n=14)

\begin{tabular}{cccccc}
\hline Variabel & \multicolumn{2}{c}{ Sebelum } & \multicolumn{2}{c}{ Sesudah } & \multirow{2}{*}{ PValue } \\
\cline { 2 - 5 } & Mean & SD & Mean & SD & \\
\hline BSF & 1.57 & 0.514 & 3.79 & 1.718 & 0.000 \\
\hline
\end{tabular}

Berdasarkan tabel 3 di atas menunjukkan konstipasi berdasarkan tipe BAB rata-rata bahwa konstipasi berdasarkan tipe $\mathrm{BAB}$ setelah dilakukan EBN Auricular rata-rata sebelum dilakukan EBN Auricular Acupressure adalah 3,79 dengan standar Acupressure adalah 1,57 dengan standar deviasi 1,718 dengan nilai $\mathrm{P}$ value 0,000 . deviasi 0,514. Sementara itu bahwa

Tabel 4 Distribusi Rata-Rata Konstipasi Partisispan Sesudah dilakukan Auricular Acupressure pada Hari ke-1 sampai Hari ke-21 di RSUPN Cipto Mangunkusumo, April $2019(n=14)$

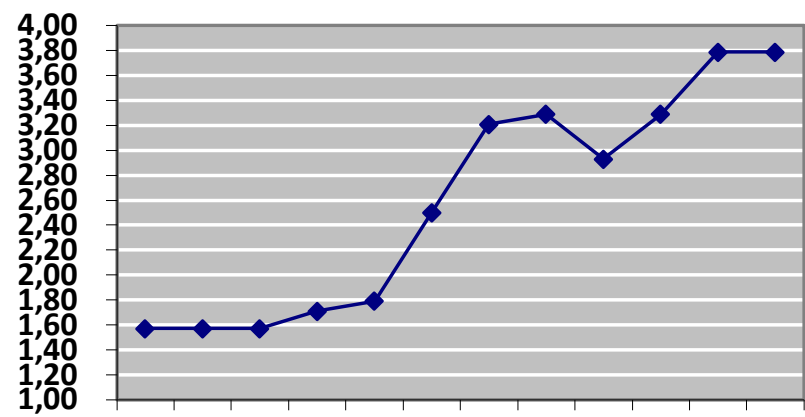

H1 H2 H3 H4 H5 H6 H7 H8 H9 H10H15 H21

Dari tabel diatas diketahui bahwa rata-rata nilai BSF pada hari pertama 1,57 , hari kedua 1,57, hari ketiga 1,57, hari keempat 1,71 , hari kelima 1,79, hari ke enam 2,50, hari ketujuh 3,21, hari kedelapan 3,29, hari kesembilan 2,93, hari kesepuluh 3,29, hari ke limabelas 3,79 dan hari ke duapuluh satu 3,79 .

\section{PEMBAHASAN}

Hasil penerapan EBN auricular acupressure untuk mengurangi konstipasi pada pasien kanker yang mendapatkan kemoterapi menunjukkan karakteritik usia responden adalah 46,7 tahun. Data ini sesuai dengan penelitian yang dilakukan oleh kementerian kesehatan RI yang menyatakan bahwa penderita kanker saat ini cenderung berada pada usia yang lebih muda dan menjadi 
penyebab kematian ke dua setelah penyakit kardiovaskuler dengan prevalensi 1,4 per 1000 penduduk (Kemenkes RI, 2014). Penderita kanker menjalani kemoterapi yang berfungsi untuk membunuh sel-sel kanker. Selain membunuh sel kanker obat anti kanker juga menyerang sel-sel sehat yang pertumbuhannya cepat. Pada pasien yang mendapatkan obat anti kanker juga mendapat obat anti mual dan muntah serta anti nyeri yang mempunyai efek samping berupa konstipasi yang menyebakan rasa tidak nyaman, nyeri dan mempengaruhi kualitas hidup pasien.

Konstipasi dapat disebabkan oleh iatrogenik, yaitu konstipasi yang terjadi terkait dengan intevensi farmakologis seperti analgetik, opioid, obat kemoterapi, anti depresan, dan anti emetik. Kejadian konstipasi pada pasien kanker meningktat berhubungan dengan pemberian obat anti kanker, pemberian anti emetik dan juga analgetik. Konstipasi kronis menyebabkan masalah lebih besar yang meningkatkan morbiditas pada pasien sehingga perlunya tindakan keperawatan mandiri yang bertujuan untuk mengurangi konstipasi (Lai et al, 2010). Salah satu intervensi keperawatan mandiri yang dapat dilakukan pada pasien kemoterapi yang mengalami konstipasi adalah Auricular Accupressure. Auricular Accupressure telah terbukti mengatasi sejumlah penyakit maupun gangguan pada system tubuh manusia (Suen, 2001).

Penerapan evidence based nursing ini berdasarkan artikel utama oleh Shin dan Park (2016), menunjukkan hasil yang efektif dalam mengatasi konstipasi pada pasien kemoterapi. Berdasarkan penghitungan statistik didapatkan hasil yang signifikan sesuai dengan apa yang didapatkan pada artikel utama. Setelah dilakukan EBN Auricular Acupressure pada pasien yang menjalani kemoterapi rata-rata tipe feses adalah 3,79 dengan standar deviasi 1,718 dengan nilai $\mathrm{P}$ value 0,000 dengan menggunakan instrument pengukuran Brestol Stool Form (BSF).

Penilaian harian menunjukkan bahwa mulai terjadi sedikit peningkatan bentuk feses pada hari keempat. Peningkatan bentuk feses menjadi lebih lunak pada hari keempat belum terlihat signifikan, dan terjadi peningkatan yang signifikan pada hari ke-6 dimana nilai BSF adalah 2,50. Peningkatan terjadi sampai hari ke-10 dengan nilai BSF 3,29 dan hari ke-15 dengan nilai BSF 3,79 dan nilai ini menetap sampai hari ke-21. Berdasarkan pada teori Zangfu dan meridian, auricular memiliki hubungan yang erat dengan bagian tubuh yang lain yang menjelaskan mengapa Auricular Accupressure dapat mengobati penyakit di 
bagian tetentu.. Auricular Accupressure mudah diterima dalam praktik klinis karena aman dan nyaman untuk dilakukan bersama dengan hasil terapi positif. Prinsip dasar di balik Auricular Accupressure dalam mengatasi konstipasi adalah pengaturan lambung dan aktivitas usus besar, serta sirkulasi $Q i$ dan darah, yang menghasilkan peningkatan cairan dan peristaltik usus, sehingga feses menjadi lebih lunak dan dapat mendorong pengeluaran feses. Hasil yang menggembirakan telah dilaporkan dalam studi sebelumnya menggunakan Auricular Accupressure dalam mengatasi konstipasi di China (Suen et al, 2001).

Penelitian lain menunjukkan bahwa dibandingkan dengan kelompok yang diberikan plasebo dan kelompok yang hanya mendapatkan perawatan biasa, efek terapi yang lebih baik dilaporkan pada peserta yang menerima Auricular Accupressure dengan menggunakan biji magnetik. Hasil ini dapat dijelaskan dengan pemilihan yang tepat dari tujuh titik akupuntur aurikularis untuk Auricular Accupressure dan stimulasi tambahan oleh efek magnetik dari biji magnetik. Semua titik akupresur yang dipilih memfasilitasi pelunakan feses oleh cairan tubuh dan feses melewati saluran pencernaan dengan waktu yang cepat untuk mencegah feses menjadi kering dan keras karena penyerapan kembali air di usus.
Selain itu, acupoint paru-paru dan San Jiao secara khusus ditargetkan untuk meningkatkan sirkulasi $Q i$ dalam tubuh untuk membantu buang air besar yang efektif. Penelitian ini juga menemukan bahwa partisipan yang mendapatkan terapi Auricular Accupressure mengalami peningkatan kualitas hidup setelah dilakukan terapi. (Li, Lee \& Suen, 2014).

Auricular Accupressure juga berpengaruh secara signifikan untuk mengurangi konstipasi, mengurangi mengejan selama buang air besar, mengurangi perasaan tidak tuntas saat buang air besar, dan perasaan adanya sumbatan pada rektum karena feses. Hasil signifikan juga didapatkan pada bentuk feses yang menjadi lebih lunak, meningkatkan kenyamanan saat buang air besar dan pergerakan usus (wang et al, 2017). Auricular Accupressure merupakan perawatan yang lebih unggul dibanding dengan perawatan rutin dalam mengatasi konstipasi. Pemilihan titik yang akan dilakukan akupresur sangat mempengaruhi efek terapi, dalam penelitian ini titik akupresur ditentukan berdasarkan prinsip pengobatan tradisoinal China dan teori Nogier yaitu rektum, usus besar, paru-paru, dan San Jiao serta subkorteks. Titik rectum dan usus besar menigkatkan peristaltik dan memberi efek feses lebih cepat melalui saluran pencernaan. Disamping itu titik pada 
paru-paru dan san jiao secara khusus ditargetkan untuk meningkatkan aliran Qi dan cairan tubuh dan untuk mendistribusikan cairan tubuh untuk meningkatkan kelembaban usus. Sementara itu subkortek mengatur fungsi saluran pencernaan meningnkatkan pergerakan atau peristaltik usus (Jing et al, 2018).

Dampak konstipasi tidak boleh diremehkan, selain kecemasan dan stres yang disebabkan oleh masalah buang air besar yang jarang dan dengan kesulitan, juga dapat dikaitkan dengan sakit perut dan dubur, distensi perut, anoreksia, mual dan muntah, retensi urin, kebingungan dan efek negatif lainnya pada pasien. Gejala-gejala terkait konstipasi ini dapat sangat memengaruhi kualitas hidup. Pengobatan konstipasi penting tidak hanya untuk menghilangkan gejala langsung tetapi juga karena komplikasi konstipasi yang tidak diobati dapat meningkatkan efek buruk pada kualitas hidup pasien. Dampak lain termasuk penyerapan obat oral yang tidak adekuat, impaksi feses, robeknya dubur, fisura rektum, wasir, obstruksi usus dan perforasi usus (Larkin et al, 2008; Liu, 2017).

Keterbatasan dalam penelitian ini adalah jumlah sampel hanya 14 orang. Sehingga diharapkan penelitian berikutnya dapat mengambil sampel yang lebih banyak dan menggunakan metode randomized control trial. Penelitian ini diharapakan dapat dijadikan sebagai salah satu referensi oeh perawat yang merawat pasien kemoterapi dan mengalami konstipasi dalam memberikan intervensi mandiri.

\section{UCAPAN TERIMA KASIH}

Ucapan terimakasih kepada pembimbing dan penguji, Dekan FIK UI, dan Direktur RS serta seluruh partisipan.

\section{DAFTAR RUJUKAN}

Belsey, J., Greenfield, S., Candy, D., \& Geraint, M. (2010). Systematic review: Impact of constipation on quality of life in adults and children. Alimentary Pharmacology \& Therapeutics, 31, 938-949. doi:10.1111/j.13652036.2010.04273.x

Chumpitazi, B. P., Self, M. M., Czyzewski, D. I., Cejka, S., Swank, P. R., \& Shulman, R. J. (2016). Bristol Stool Form Scale reliability and agreement decreases when determining Rome III stool form designations. Neurogastroenterology \& Motility, 28, 443-448. doi:10.1111/nmo.12738

Continence Foundation of Australia (2014), "Sembelit dan Mengendalikan Isi Perut (Constipation and Bowel Control)". diunduh dari http//:www. continence.org.au pada tanggal 20 Februari 2019

DeLaume, S C \& Ladner, P K (2011). Fundamental of Nursing. Standart \& Practice (4th Ed). Delmar Chengenge Learning 
Gori, F \& Firenzuoli, F. (2007) "Ear acupuncture in European traditional medicine,"

Evidence-Based Complementary and Alternative Medicine, vol. 4, supplement 1, pp. 1316.

Hanai, A., Ishiguro, H., Sozu, T., Tsuda, M., Arai, H., Mitani, A., \& Tsuboyama, T. (2016). Effects of a self-management program on antiemetic-induced constipation during chemotherapy among breast cancer patients: A randomized controlled clinical trial. Breast Cancer Research and Treatment, 155, 99-107. doi:10.1007/s10549-015$3652-4$

Jing, X., Liu, J., Wang, C., Ji, M., Chen, X., \& Mei, Y. (2018). Complementary Therapies in Clinical Practice Auricular acupressure is an alternative in treating constipation in leukemia patients undergoing chemotherapy: $A$ systematic review and meta-analysis. Complementary Therapies in Clinical Practice, 31, 282-289. https://doi.org/10.1016/j.ctcp.2018.03.0 05 Kementrian Kesehatan RI (2014).

Kim, S. H., Lee, R., \& Lee, K. S. (2009). Symptom clusters in patients with breast cancer. Korean Journal of Adult Nursing, 21, 705-717

Larkin, P. J., Sykes, N., Centeno, C., Ellershaw, Elsiner, F., Eugene, B., ... Zuurmond, W. (2015). The management of constipation in palliative care: clinical practice recommendations. Palliative Medicine, 22, 796-807.

Li, M. K., Lee, T. F. D., \& Suen, K. P. L. (2014). Complementary effects of auricular acupressure in relieving constipation symptoms and promoting disease-specific health-related quality of life: A randomized placebo- controlled trial \&. Complementary Therapies in Medicine, 22, 266-277. https://doi.org/10.1016/j.ctim.2014.01. $\underline{010}$

Lin, Y. W., \& Hsieh, C. L. (2014) “Auricular electroacupuncture reduced inflammation-related epilepsy accompanied by altered TRPAI, $p P K C \alpha, p P K C \varepsilon$, and $p E R k 1 / 2$ signaling pathways in kainic acid-treated rats," Mediators of Inflammation, vol.2014, Article ID 493480, 9 pages.

Liu, X., Feng, L., Nicole, R., \& Wong, N. (2017). European Journal of Integrative Medicine Review article Effects of auricular acupressure therapy for preventing constipation in leukemia patients undergoing chemotherapy: Protocol for a systematic review. European Journal of Integrative Medicine, 15(September), 42-46. https://doi.org/10.1016/j.eujim.2017.09 .002

Lee, E. J., \& Frazier, S. K. (2011). The efficacy of acupressure for symptom management: A systematic review. Journal of Pain and Symptom Management, 42, 589- 603. doi:10.1016/j.jpainsymman.2011.01.00 7

Park, J. H., Jun, E. Y., Kang, M. Y., Joung, Y. S., \& Kim, G. S. (2009). Symptom experience and quality of life in breast cancer survivors. Journal of Korean Academy of Nursing, 39, 613-621. doi:10.4040/jkan.2009.39.5.613

Shin, J., \& Park, H. (2016). Effects of Auricular Acupressure on Constipation in Patients With Breast Cancer Receiving Chemotherapy: A Randomized Control Trial. Western Journal of Nursing Research, 1-17. https://doi.org/10.1177/0193945916680 $\underline{362}$ 
Suen, L. K. P., Wong, T. K. S., \& Leung, A. W. N. (2001). Is there a place for auricular therapy in the realm of nursing? ComplementaryTherapies in Nursing \&Midwifery, 7, 132-139. https://doi.org/10.1054/ctnm.2001.0565

Suen, L. K., Wong, T. K., Chung, J. W., \& Yip, V. Y. (2007). Auriculotherapy on low back pain in the elderly. Complementary Therapies in Clinical Practice, 13, 63-69. doi:10.1016/j.ctcp.2006.10.005

Wang, P., Hsu, C., Liu, C., Lai, T., Tzeng, F., \& Huang, C. (2019). Effect of acupressure on constipation in patients with advanced cancer. Supportive Care in Cancer.

Yan, X. K., Chui, J. M., \& Yang, Y. Q. (2005). Development on clinical treatment of constipation with acupuncture and moxibustion. World Journal of Acupuncture - Moxibustion, 15(3), 56-64.

Yang, L. H., Duan, P. B., Du, S. Z., Sun, J. F., Mei, S. J., Wang, X. Q., \& Zhang, Y. Y. (2014). Efficacy of auriculotherapy for constipation in adults: A systematic review and meta-analysis of randomized controlled trials. The Journal of Alternative and Complementary Medicine, 20, 590-605. doi:10.1089/acm.2013.0324

Zhao, Y. X., He, W., Jing, X. H. et al., (2012) "Transcutaneous auricular vagus nerve stimulation protects endotoxemic rat from lipopolysaccharide- induced inflammation," Evidence-Based Complementary and Alternative Medicine, vol. 2012, Article ID 627023, 10 pages. 